\title{
O CATOLICISMO DENTRO DO CONTEXTO POLÍTICO, SOCIAL E INTELECTUAL DO BRASIL REPUBLICANO: O PERÍODO DA REPÚBLICA DA ESPADA
}

\author{
Liliane Andréia Splendor (Mestrado em História - UEM) \\ Prof. Dr. Reginaldo Benedito Dias (Orientador) \\ lilispl@,gmail.com
}

\section{RESUMO}

A mudança de regime político ocorrida no Brasil em novembro de 1889 provocou uma série de transformações em todas as áreas, algumas radicais e outras mais brandas. Uma dessas alterações, decorrentes da decretada separação entre o Estado e a Igreja Católica, foi a retirada do catolicismo do seu posto de religião oficial do país. No entanto, não é difícil verificar que a mesma continuou exercendo significativa influência durante o primeiro quinquênio do regime republicano, não só política, mas também social e intelectualmente. Apoiando-se sobre leituras de diversos autores, este artigo procura apontar a influência da Igreja Católica no desenvolvimento inicial do republicanismo brasileiro, expondo suas estratégias de atuação, demonstrando que ela utiliza a consciência popular para atingir os seus fins, para intervir em áreas que supostamente deveriam ser de domínio único e exclusivo do Estado a partir de então, e principalmente mostrar a influência de uma religião sobre o processo de desenvolvimento de uma nação.

Palavras-chave: Igreja Católica. Estado. Catolicismo.

\section{INTRODUÇÃO}

Tomando como objeto de estudo um importante documento da Igreja Católica brasileira, a Pastoral Coletiva do Episcopado Brasileiro, publicada no ano de 1890, e apoiando-se sobre obras escritas por vários autores que levam a refletir sobre os mais diversos aspectos que permeiam o tema central, este artigo procura evidenciar como a Igreja Católica, enquanto instituição há muito solidificada no Brasil, posicionou-se e atuou imediatamente após a Proclamação da República e durante a denominada República da Espada.

Em outras palavras, visando o aprofundamento de conhecimentos a respeito da presença da Igreja Católica no Brasil, buscou-se, através da análise e comparação desses diversos textos, compreender a relação existente entre ela e o Estado antes, durante e logo após a Proclamação da República, em 1889.

Fez-se a opção de analisar o posicionamento e a atuação da Igreja Católica neste período para que seja possível, além de rebater o suposto sucesso na implantação do laicismo na sociedade brasileira, atingir mais um dos objetivos de uma pesquisa ainda em andamento, que é o de mostrar a influência de uma religião sobre o processo de desenvolvimento de uma nação.

A princípio, sabe-se que o republicanismo no Brasil foi concebido principalmente pelos expoentes da doutrina liberal, mas o mesmo também acabou por 


\section{SEMINÁRIO DE PESQUISA EM CIÊNCIAS HUMANAS - SEPECH \\ Humanidades, Estado e desafios didático-científicos \\ Londrina, 27 a 29 de julho de 2016}

sofrer alguma influência do Positivismo de Augusto Comte e das variantes dessa linha, desenvolvidas por alguns indivíduos que haviam sido discípulos dele, como Pierre Laffitte, por exemplo.

Os responsáveis pela elaboração do esboço inicial e posteriormente do documento oficial que viria a servir de símbolo da separação jurídica e irreversível entre o Estado brasileiro e a Igreja Católica, assim como os demais adeptos do regime republicano, acreditavam que esta era a grande responsável pela situação de "atraso" material, ideológico e científico do país. Com a desoneração do Estado em relação à Igreja, a laicização foi recebida de "braços abertos" pelo Governo Provisório.

A sociologia de Comte, na tentativa de suplantar, de certa forma, o ideário liberal, ambicionava uma reforma intelectual e social capaz de formular uma religião da humanidade em substituição ao Deus cristão. Entre os positivistas circulava a crença de que o Catolicismo havia surgido para suprir a necessidade imediata de uma disciplina completa. Baseados nessa concepção de que a sabedoria neutralizava os vícios, procuravam criar uma religião verdadeiramente universal.

O Brasil acabou então por tornar-se solo fértil para as ideias dessas duas doutrinas, uma vez que acabara de entrar em uma fase de transição ideológica e necessitava de novas bases de sustentação para o seu desenvolvimento.

Mas estas mesmas ideias vieram posteriormente a oferecer novas brechas para atuação da Igreja Católica na sociedade brasileira. Esta, através do catolicismo ultramontano, um movimento reacionário conservador da Igreja Católica de Roma que objetivava reestruturar a sociedade brasileira em seu conjunto de áreas e de acordo com seus preceitos, estabeleceu as bases e colocou em prática sua política de reação diante do extremo racionalismo que estava sendo disseminado pelo regime republicano. Através de suas particularidades ele vai combatendo os espíritos exaltados e devolvendo à sociedade brasileira o que foi apenas aparentemente retirado dela: sua aura teológica.

Conforme dito anteriormente, um significativo documento da Igreja Católica brasileira é utilizado como fonte primária desta pesquisa em andamento, a Pastoral Coletiva do Episcopado Brasileiro. Este foi escrito e publicado no ano de 1890, entre a publicação do Decreto n ${ }^{0}$ 119-A e a promulgação da Constituição de 1891, e apresentase como um esboço fiel da reação não apenas dos bispos que se reuniram para escrevêla, mas também de toda comunidade realmente católica frente à separação da Igreja e do Estado e às consequências que esse fato gerou na prática.

A escolha de um documento escrito e publicado por figuras importantes da hierarquia católica brasileira vem para corroborar um aspecto que será evidenciado ao longo da pesquisa: o principal meio utilizado pela Igreja Católica para reaver sua posição de influência política e social no país foi a exortação das mentes, principalmente daqueles que integravam os grupos de elite do país. Através da publicação de documentos ela procurava atingir o nível mais profundo da consciência desses indivíduos, levando-os a formar um novo tipo de pensamento ou a reforçar os antigos valores já absorvidos. 


\section{SEMINÁRIO DE PESQUISA EM CIÊNCIAS HUMANAS - SEPECH \\ Humanidades, Estado e desafios didático-científicos \\ Londrina, 27 a 29 de julho de 2016}

\section{O CATOLICISMO DENTRO DO CONTEXTO POLÍTICO, SOCIAL E INTELECTUAL DO BRASIL DURANTE O PERÍODO DA REPÚBLICA DA ESPADA}

Ao enveredar-se pelo caminho que conduz à rememoração dos momentos que antecederam a instauração do regime republicano no Brasil, em pouco tempo percebe-se que estes se encontram profundamente marcados pelos efeitos da instabilidade política e econômica e da incapacidade do Imperador e dos grupos que lhe apoiavam de promover a reversão desse quadro.

Indisposta com o Exército, que se encontrava totalmente insatisfeito com o fato de receber cada vez menos o auxílio do Estado após o término da Guerra do Paraguai, com os grandes proprietários de terra, que após a Abolição da escravidão negra viram-se despojados de sua maior fonte de mão-de-obra, e com a Igreja Católica, que sentira-se profundamente agredida após ter sido decretada a prisão de dois dos mais importantes representantes da alta hierarquia do clero católico brasileiro durante a batalha empreendida contra a Maçonaria, a Monarquia só fazia perder sua força e aceitação entre os grupos que compunham a sociedade daquele período.

Diante desses conflitos internos, fazia-se necessário que o sistema político realizasse algumas mudanças urgentes, de modo a possibilitar a rearticulação dos grupos e a retomada de sua capacidade de governar soberanamente sobre os demais. No entanto, foram muitos os obstáculos enfrentados, o que terminou por ocasionar a prostração da família imperial e de sua base aliada.

Essa falta de interesse e de forças da Monarquia para lutar pela sua antiga posição de supremacia aliada às questões acima citadas (Questão Militar, Questão Agrária e Questão Religiosa) acabou abrindo espaço para o surgimento do interesse em substituir o então inadequado regime político por outro capaz de dar conta das necessidades atuais.

Observando o que ocorria em outros países e levando em consideração algumas histórias de sucesso trazidas na bagagem dos imigrantes europeus e norte-americanos que desembarcavam em número cada vez maior no Brasil para suprir a necessidade de mão-de-obra nas lavouras e no ainda pouco expressivo setor industrial, algumas ideologias até então pouco representativas no país passam a ganhar força entre os grupos sociais.

Inspirados pela Revolução Francesa, pelo Iluminismo e pelo federalismo norteamericano, os republicanos surgem com uma proposta inovadora para a nação brasileira: ao invés do Estado governar os indivíduos, os indivíduos governariam o Estado. Assim, tratam de se lançar na tarefa de reformar o país. E sua propaganda, apesar de fracassar inicialmente, pouco a pouco, com o agravamento da crise econômica e consequentemente da crise política, foi conquistando as mentes que iam se abrindo para novas possibilidades. Entre estes adeptos estavam os liberais e positivistas descontentes com os rumos que a nação ia tomando e que vinham nutrindo planos ambiciosos para ela.

Em 1889, após o acirramento dos conflitos internos,

muitos militares, liderados por Deodoro e Benjamin Constant, sentiam os tempos maduros para a purificação do corpo político. No começo de novembro, decidiram derrubar o Império antes do dia 20 , quando o 


\section{SEMINÁRIO DE PESQUISA EM CIÊNCIAS HUMANAS - SEPECH \\ Humanidades, Estado e desafios didático-científicos \\ Londrina, 27 a 29 de julho de 2016}

Parlamento devia inaugurar uma sessão. Um boato de que fora ordenada a prisão de Deodoro apressou o golpe, que ocorreu no dia 15 de novembro (ELLIS et al., 2004, p. 302).

No que diz respeito ao posicionamento da Igreja Católica, esta enxergava esse processo de mudança sob a ótica da desconfiança, uma vez que ao longo de todo o período de política imperial, vinha caminhando ao lado do governo. O Estado atendia aos seus interesses (principalmente financeiros) e ela atendia aos interesses do Estado (principalmente no que diz respeito à legitimação do regime político e à manutenção da ordem pública). Mas também não se pode deixar de citar o lado negativo dessa relação de dependência, pelo fato de haver interferência direta nas decisões e comportamentos de uma parte em relação a outra.

Mas a possibilidade dessa aliança deixar de existir passou a ser uma ameaça cada vez mais forte nos anos finais da Monarquia e a partir do momento em que a República foi proclamada. Liberais, positivistas, republicanos enfim, desejavam dar vez a uma sociedade laica, ou seja, livre da aura transcendental fornecida pelo catolicismo e aberta para a manifestação dos mais diversos credos e pensamentos.

Ao proeminente liberalismo cabia a função do não-privilégio, ou seja, do alto de seu posto imperativo, era sua incumbência fornecer um lugar social para todas as manifestações religiosas e também a igualdade jurídica. Segundo Roberto Romano (através da contribuição do pensamento hegeliano), "afastar o domínio religioso e instaurar a laicidade do aparelho administrativo sintetizam o ideário republicano de maneira certa" (1979, p. 97).

Já o positivismo, além de se colocar contra a livre atuação da Igreja Católica, por também considerá-la uma ameaça, posicionou-se contra o excesso de liberdade que se planejava oferecer aos indivíduos, principalmente no que tangia à educação. Para aquele, somente a doutrina positivista, através de seu sábio cientificismo, seria capaz de dar conta das necessidades do novo Estado e dos questionamentos individuais.

$\mathrm{Na}$ reta final do regime imperial essas ideologias ganharam maior publicidade. Mas ao mesmo tempo a Igreja Católica tratava de colocar em prática uma política centralizadora, denominada ultramontanismo, objetivando a expansão mundial do catolicismo, através principalmente da maior disciplinarização do clero (de forma a conduzi-lo por um caminho de retidão e comprometimento e retirá-lo do estado de ignorância intelectual em que se encontrava) e da realização de missões (de modo a assistir àquelas regiões que ainda não contavam com uma presença constante de figuras religiosas em sua rotina diária).

Em busca da retomada de sua soberania, a religiosidade eclesiástica direcionouse também para a população em geral, justamente o núcleo com menor representatividade e influência política. Aí desenvolveu pregações de maior cunho sentimental, objetivando "se fazer Povo" (1979, p. 102). Por esta atitude, foi rechaçada pelo Estado, por considerar-se que estes discursos integravam uma política antiliberal.

Além desse aspecto, também a infalibilidade do Papa, declarada e imposta através da doutrina ultramontana, configurou-se como outra ameaça ao Estado moderno (antirreligioso), pois esse modelo voltava-se "contra o laicismo no domínio da coisa pública e no pensamento" (ROMANO, 1979, p. 103). Além disso, "a comunidade eclesiástica, pelo simples fato de continuar existindo, obstava a divisão radical entre o 


\title{
XI SEMINÁRIO DE PESQUISA EM CIÊNCIAS HUMANAS - SEPECH \\ Humanidades, Estado e desafios didático-científicos \\ Londrina, 27 a 29 de julho de 2016
}

domínio privado, onde reina o indivíduo, e o público, onde se estabelece o espaço da cidadania" (ROMANO, 1979, p. 105).

Instaurada a República a deflagração da disputa pela consciência dos indivíduos entre um Estado coercitivo e uma Igreja persuasiva torna-se ainda mais evidente. A Igreja estava em processo de recuperação e se negava a ocupar-se somente com os que já a seguiam, o que tornou impossível uma conciliação entre o catolicismo e o liberalismo. Ficavam então mais severas as críticas da doutrina liberal à tentativa de uma dominação católica. Argumentava-se que a Igreja utilizava um poder hostil, que punha em desigualdade as instituições civis, assim ela é colocada como algo pernicioso ao regime político que deve ser vigorosamente combatido.

"Coerentes continuadores do liberalismo clássico, os propagandistas da República concordavam sobre a anulação da Igreja na cena pública e nos assuntos seculares. Buscavam garantir, acima de tudo, ao Estado, o direito exclusivo de imposição legal, (...)" (ROMANO, 1979, p. 106). A laicidade do Estado tornara-se radical diante da Igreja: esta deveria ser totalmente separada dele para que se pudesse assegurar o progresso e a segurança pública.

E é isso o que ocorre, apesar dos fortes apelos e das tentativas de negociação por parte do clero católico junto aos representantes do Governo Provisório. A separação entre a Igreja Católica e o Estado é oficialmente promulgada em 7 de janeiro de 1890, através do Decreto 119-A. Este

\begin{abstract}
dava lugar a um estado não-confessional, em que o nome de Deus era riscado dos atos públicos, o catolicismo nivelado às seitas protestantes minoritárias no mesmo regime de liberdade religiosa, os símbolos religiosos afastados de todos os edifícios públicos, o casamento civil instituído, as propriedades de "mão-morta" ameaçadas de expropriação. Tudo isso configurava um regime liberal que tinha sido claramente condenado pelo magistério oficial da Igreja, particularmente pelo Syllabus de Pio IX (PINHEIRO et al., 2006, p. $351)$.
\end{abstract}

Outros decretos viriam posteriormente a impor outras sanções, tomadas pela Igreja Católica e por seus seguidores como uma terrível afronta. Estes já se faziam sentir como o prenúncio do que viria a ser instituído pela primeira constituição republicana, em 1891. Diante disso ela trata de posicionar-se a respeito da sua nova condição dentro da sociedade brasileira e de reagir contra a usurpação de sua influência pelo Estado.

Ambas atitudes foram levadas a cabo através da publicação da Pastoral Coletiva do Episcopado Brasileiro, em maio de 1890. Assim como as encíclicas papais, essa carta, gestada e trazida à luz pelo conjunto de bispos brasileiros do período, tinha o intuito de adentrar a consciência dos indivíduos e influenciar o seu modo de pensar e agir, levando-os à compreensão de que não é possível que uma nação se desenvolva e progrida de modo pleno sem o auxílio da religião, sem a ativa participação do catolicismo.

E eis que a sua separação do Estado vista por um outro ângulo também havia the proporcionado ganhos. Decretado o fim do padroado, a Igreja viu-se livre da interferência do Estado em seus assuntos internos, o que lhe permitiu voltar a publicar seus documentos oficiais sem sofrer nenhum tipo de censura. Aproveitou-se dessa 


\section{SEMINÁRIO DE PESQUISA EM CIÊNCIAS HUMANAS - SEPECH \\ Humanidades, Estado e desafios didático-científicos \\ Londrina, 27 a 29 de julho de 2016}

liberdade para exortar não só os integrantes do clero católico, mas também, e principalmente, as elites e demais classes sociais a lutarem pela reconquista do espaço de atuação da Igreja Católica. Esta continuaria se dedicando com afinco à esfera espiritual, mas também estava decidida a manter seu posto de instituição atuante e influente na esfera temporal.

Ivan A. Manoel colabora para a confirmação deste comportamento ao escrever que

(...) a hierarquia católica não limita sua ação e a de seus fiéis ao campo devocional. Bem ao contrário, a Igreja se atribui e aos seus fiéis o direito e o dever de intervirem no social e no político para garantirem que as estruturas sociais sejam transformadas em conformidade com a doutrina católica $(2004$, p. 20).

Dessa forma, para além de sua aparência geral, de mero documento norteador do clero e dos fiéis católicos nesta sociedade reconstruída a partir da mescla de novos e velhos princípios, de novas e velhas práticas, a carta pastoral assumiu as vezes de uma verdadeira cartilha política da Igreja Católica. Ao expor minuciosamente os problemas resultantes do divórcio litigioso entre ela e o Estado, suas linhas acabam por desnudar as incoerências e negligências que são próprias desse grande algoz do catolicismo, o republicanismo liberal-positivista, mas principalmente elas acabam por se transformar na melhor e mais eficaz estratégia de ação desse mesmo catolicismo, que ao fazer chegar a toda a população as ideias simples (mas bem elaboradas) aí contidas foi capaz de levá-la a enxergar novamente a religião como o meio mais viável e coerente de ordenação social.

Para trabalhar a consciência não só do povo mais humilde, mas subliminarmente também das elites, o Episcopado Brasileiro elege três pontos principais de reflexão, que são apontados na introdução do documento e desenvolvidos nas respectivas três partes que a seguem. São eles, segundo os próprios elaboradores:

E primeiramente, que se há de pensar dessa separação da Igreja e do Estado, que infelizmente está consumada entre nós pelo decreto do governo provisório de 7 de janeiro do corrente ano? É, porventura, em si, boa, e deve ser aceita e aplaudida por nós católicos?

Em segundo lugar, que havemos de pensar do decreto enquanto franqueia liberdade a todos os cultos?

Em terceiro lugar, enfim, que temos de fazer os católicos do Brasil em face da nova situação criada à nossa Igreja? (RODRIGUES, 1981 apud EPISCOPADO BRASILEIRO, 1890).

Discorrendo sobre esses três pontos principais ao longo de todo o documento, os bispos brasileiros tratam de mostrar não só as consequências da retirada do catolicismo de seu posto de religião oficial do Estado, mas também de exortar a população brasileira a lutar contra a imposição definitiva do laicismo que seria realizada através da promulgação da Constituição de 1891.

Esta atitude de expectativa da Igreja em face da Constituição a ser elaborada explicava-se pela atuação na capital da República de um 


\section{SEMINÁRIO DE PESQUISA EM CIÊNCIAS HUMANAS - SEPECH \\ Humanidades, Estado e desafios didático-científicos \\ Londrina, 27 a 29 de julho de 2016}

grupo organizado de positivistas, cuja influência se julgava grande, e pela propagação difusa de suas ideias junto à intelectualidade da época. (...) Esta influência do positivismo, se bem que real, aparecia exageradamente aumentada aos olhos dos homens da Igreja, que tendiam a lhe atribuir toda sorte de manobras anticlericais. Mais profunda na realidade seria a influência de uma vertente anticlerical do neoliberalismo da época, acirrada e generalizada durante o pontificado de Pio IX por reação contra o ultramontanismo que o caracterizou e sobretudo pela polêmica em torno da "questão romana" (PINHEIRO et al., 2006, p. 352).

Alguns meses depois esse sentimento de apreensão, de desconfiança, tornar-se-ia justificado pela promulgação de alguns artigos constitucionais considerados bastante ofensivos pelo clero católico. São eles:

Sujeição dos bens da Igreja à lei de "mão-morta", reconhecimento e obrigatoriedade do casamento civil, laicização do ensino público, secularização dos cemitérios, proibição de subvenções oficiais a qualquer culto religioso, proibição de se abrirem novas comunidades religiosas, especialmente da Companhia de Jesus, inelegibilidade para o Congresso de clérigos e religiosos de qualquer confissão (PINHEIRO et al., 2006, p. 352-53).

Já em certa medida preparada internamente para receber esse golpe que objetivava enfraquecê-la ainda mais, lança mão "de uma teoria teológico-política" (PINHEIRO et al., 2006, p. 353) para organizar a sua reação, por saber que esta seria a melhor ferramenta a ser utilizada na luta pela recobrada da sua influência. Se as doutrinas liberal e positivista haviam ludibriado a muitos intelectuais da época, ela haveria de lutar de igual para igual. Através da doutrina ultramontana ela iria tratar de formar novos intelectuais e reformar os antigos. Para isso contou com a expressiva ajuda do Padre Júlio Maria, que através da materialização e difusão de seu pensamento tratou de auxiliar a Igreja Católica nessa árdua tarefa de adentrar a consciência dos indivíduos pertencentes aos diversos grupos que compunham a sociedade brasileira.

Para ele, a palavra também era uma importante aliada na luta contra a tentativa de laicização total do Estado. Assim, acabou por tornar-se um dos principais apoiadores e divulgadores da Pastoral Coletiva do Episcopado Brasileiro. Argumentava ele que neste momento tão conturbado pelo qual a sociedade brasileira estava passando

só a pregação poderá iluminar as trevas em que jazem tantos espíritos de nossas classes dirigentes, os quais, sem instrução religiosa, ignorando a doutrina católica, cujos princípios não lhes são ensinados, nutrem os mais absurdos preconceitos contra a Igreja. Esses mesmos, uma vez esclarecidos, hão de ser auxiliares do clero nas reivindicações a que a religião tem direito, em face da República, num país cuja imensa maioria é de católicos, e que não pode contemplar impassível na bandeira - o lema, nas escolas do país - a influência da seita positivista (MARIA, 1981, p. 116). 


\section{SEMINÁRIO DE PESQUISA EM CIÊNCIAS HUMANAS - SEPECH \\ Humanidades, Estado e desafios didático-científicos \\ Londrina, 27 a 29 de julho de 2016}

Mas, além da publicação de documentos, como a Pastoral Coletiva, e de artigos em veículos da imprensa católica, e da intensiva pregação nos locais de culto e festas católicos, também foram adotados como métodos reacionários o reavivamento das ordens e congregações religiosas (através do estabelecimento de novas unidades em vários pontos do território brasileiro e do aumento do numerário humano através da formação de novos padres e da incorporação de religiosos e religiosas vindos de outros países); a abertura de novas escolas (que atendiam também as classes mais baixas da população) e a formação de professores capacitados a ministrar o conhecimento de acordo com as diretrizes do ensino católico; a criação de grupos voltados para a realização de obras de caridade; o constante diálogo com os membros do governo republicano a fim de negociar a adoção de medidas burocráticas não radicais.

Todas essas medidas corroboraram para que os grupos sociais passassem a notar a importância da atuação da Igreja Católica em conjunto com o Estado, uma vez que este demonstrava-se falho em atender sozinho a todas as necessidades que a nova realidade sócio-política impunha. $\mathrm{O}$ auxílio dos funcionários e dos fiéis católicos em grande medida ajudava a desonerar o governo de Deodoro da Fonseca e de Floriano Peixoto das cargas que um sistema político supostamente voltado para o povo lhes eram impostas.

Com o passar do tempo compreendeu-se que seria muito mais profícuo para ambas as partes procurar meios de conciliação e de trabalharem juntos em prol da reconstrução da sociedade civil. Não que seus posicionamentos ideológicos tenham sido alterados, mas procurou-se negociá-los em nome do velho jogo de interesses. Assim, o governo contaria com mais um aliado na restauração da ordem e na promoção do progresso e a Igreja iria aos poucos retomando seu poder de influência sócio-política.

\section{CONCLUSÕES PARCIAIS}

Apesar de ter adquirido as bases para uma definição mais concreta através do laicismo que se estabeleceu com a separação entre Igreja e Estado, historicamente, o processo de desenvolvimento do regime republicano fez-se sobre moldes cristãos. Através das particularidades da sua oscilante, mas sempre ativa participação na sociedade brasileira, a Igreja Católica foi capaz de influenciar significativamente na formação do novo cenário político do país e na vida dos seus muitos cidadãos.

Não pode-se negar que a mesma sofreu um duro golpe e sentiu-se enfraquecida ao ser retaliada pelo Estado e com a consequente perda de seus muitos privilégios, principalmente os de cunho financeiro. Mas esta separação acabou por revelar-se uma via de mão-dupla. Ao libertar-se do controle estatal, a Igreja Católica brasileira viu-se munida de uma autonomia para organizar-se internamente, o que foi, além de muito conveniente, de fundamental importância para torná-la mais coesa, unida e permitir uma recobrada gradual de sua força e influência.

Em toda a história da Igreja, as publicações realizadas pelos membros do clero católico aparecem como um dos principais meios de evangelização, de doutrinação, o que justifica o emprego de uma carta pastoral nesse momento confuso de troca de regime político. Segundo o Episcopado "é o seu primeiro poder, é o magistério, pela qual ela tem mantido a unidade da fé, a uniformidade da doutrina" (RODRIGUES, 1981 apud EPISCOPADO BRASILEIRO, 1890). É a própria palavra, seja ela escrita ou 


\section{SEMINÁRIO DE PESQUISA EM CIÊNCIAS HUMANAS - SEPECH \\ Humanidades, Estado e desafios didático-científicos \\ Londrina, 27 a 29 de julho de 2016}

verbalizada oralmente, que comprova a importância e a supremacia católica, pois basta realizar uma pequena busca pelas fontes históricas mais antigas para tomar conhecimento da longa história de lutas do catolicismo e de como sua presença secular o coloca em vantagem diante das novas crenças que iam se desenvolvendo no Brasil. A astuta argumentação dos representantes da Igreja Católica foi a forma primeira utilizada para barrar o avanço do Protestantismo e de outras "seitas" religiosas desencadeado pela entrada de imigrantes no país. Era a admoestação de transformando em poder de persuasão.

Poder este que foi sábia e calculadamente utilizado para voltar a interferir no destino do país e para reconstruir a sua imagem de instituição indispensável ao sadio desenvolvimento da nação. Prestando assistência nos mais diversos ramos da sociedade e empenhando-se na reformulação do pensamento intelectual brasileiro, a Igreja Católica foi de tal forma penetrando outra vez no campo da política que tornou-se impossível para os governantes negar a importância da mesma durante os primeiros anos do regime republicano.

Satisfazer tanto aos seus próprios interesses quanto aos interesses do Estado colocava-se como o objetivo primordial, afinal a Igreja Católica também zelava pela saúde política e pelo bem-estar social do país. Depois dos desentendimentos e atritos iniciais entre ambos, o reconhecimento da necessidade de colaboração mútua viria a amainar esse clima de tensão política e religiosa. A compreensão por parte dos governantes de que as concessões feitas ao catolicismo resultariam em benefícios para o Estado acabou por tornar fértil o solo em que o clero e os fiéis católicos iam replantando suas ideias. De semente em semente implantada nas brechas abertas pelo poder laico, o catolicismo foi reconquistando o território das consciências e recolocando a religião como força propulsora da ordenação social já nos primeiros cinco anos do novo sistema político.

\section{REFERÊNCIAS}

ELLIS, Myrian [et al.]. O Brasil Monárquico, v.6: Declínio e Queda do Império. História Geral da Civilização Brasileira, t. 2. Rio de Janeiro: Bertrand Brasil, 2004.

EPISCOPADO BRASILEIRO. Pastoral Coletiva do Episcopado Brasileiro (1890). In: RODRIGUES, Anna Maria Moog (Org.). A Igreja na República. Coleção Pensamento Político Republicano. Brasília: Editora Universidade de Brasília, 1981, p. 17-58.

MANOEL, Ivan A. O Pêndulo da História: Tempo e Eternidade no Pensamento Católico (1800-1960). Maringá: EDUEM, 2004.

MARIA, Júlio. A Igreja e a República. Brasília: Editora Universidade de Brasília, 1981.

PINHEIRO, Paulo Sérgio [et al.]. O Brasil Republicano, v. 9: Sociedade e Instituições (1889-1930). História Geral da Civilização Brasileira, t. 3. Rio de Janeiro: Bertrand Brasil, 2006. 
XI SEMINÁRIO DE PESQUISA EM CIÊNCIAS HUMANAS - SEPECH

Humanidades, Estado e desafios didático-científicos

Londrina, 27 a 29 de julho de 2016

ROMANO, Roberto. Brasil: Igreja Contra Estado. São Paulo: Kairós, 1979. 